\title{
Foreign medical graduates and U.S. physician supply: old issues and new questions
}

\author{
Stephen S. Mick \\ Department of Health Services Management and Policy, School of Public Health, \\ University of Michigan, Ann Arbor, MI, USA
}

Accepted 2 March 1993

\begin{abstract}
Summary
Recent increases in the number of foreign medical graduates (FMGs) in U.S. hospitaltraining positions raise new questions about the future role of FMGs in U.S. medicine. Despite an historical surplus of physicians, forces such as greater demand for resident house officers, stabilization in undergraduate medical education enrollment, increase in demand for medical services, growth in both the number of women in medicine and physician employment in group practices, and continuing imbalances in the distribution of physicians favor FMG migration to the United States. Health system reform must be sensitive to the historical, current, and future role FMGs play in medical care delivery, especially in regard to service in underserved areas, specialties, and employment settings.
\end{abstract}

Foreign Medical Graduates; Physician Supply; United States

\section{Introduction}

Since at least the publication and widespread dissemination in 1980 of the Summary Report to the Secretary by the Graduate Medical Education National Advisory Committee (GMENAC) [1], reinforced by studies such as those of the U.S. Bureau of Health Professions [2] and the American Medical Association [3], there has been a perception that the United States has a surplus of physicians. Despite criticisms of the GMENAC study [4,5], the idea of a surplus gained adherents and became the basis of U.S. public policy

Address for correspondence: Professor S.S. Mick, Department of Health Services Management and Policy, School of Public Health, University of Michigan, 1420 Washington Heights, Ann Arbor, MI 48109, USA. 
to resist further increases in the number of new medical schools and of medical graduates. The view of the state of physician supply relative to demand was confidently characterized as being out of balance, and the United States began steps to let both direct intervention and market forces winnow the excess supply as well as to enjoy the benefits of the supply via its diffusion into previously underserved areas, specialties, and institutions.

One focus for constraining physician supply was foreign medical graduates (FMGs). Regardless of the position a person took on FMGs, most thought that the United States would reduce its reliance on these foreign-educated physicians, and a number of direct and indirect steps to inhibit their arrival for post-graduate hospital residencies were proposed [6].

A little more than a decade later, however, once confident predictions of the looming surplus of physicians and the certainty that many had about the direction of public policy with regard to physician supply have seemed to weaken. What has happened to erode the earlier confidence? How can this be when the United State's physician supply has grown from 467679 in 1980 to an estimated 601060 in 1990, a $28.5 \%$ increase [7]? Part of the problem, long recognized by observers of physician supply, is that an increase in supply does not automatically mean a change in distribution across location and specialty of practice as well as employment setting. Another part of the problem, as Ginzberg effectively argues [8], lies in the United States' lack of systematic and consistent attention to physician supply issues. Except for small clusters of researchers, policy analysts, and medical educators, physician supply and distribution questions have nearly vanished from U.S. health policy deliberations. The unfortunate result is that careful study and analysis, revision of assumptions and projections and mid-course policy changes are wanting, until in a new cycle of activity, the accumulation of changes and problems force themselves onto the health policy scene. In the spirit of renewing discussion and debate, this paper seeks to describe some of important changes that took place during the 1980 s in U.S. health care and to speculate on their possible impact on the current physician supply situation, especially with respect to FMGs.

\section{Foreign medical graduates}

The presence of FMGs in U.S. medicine, a complex question in its own right, has nevertheless often been simplistically attributed to 'gap filling' in medical practice. This is a controversial subject, but one that continues to be raised whenever the subject is FMGs. Past and recent studies show that 'gap filling' does take place with respect to underserved geographical areas, specialties, and employment practice settings, but not to the extent that it is sometimes described [9-11]. FMGs also find permanent employment in the United States for the same reason U.S.-educated physicians do: opportunities for specialization, insatiable public demand for medical services, physician-induced demand abetted by still relatively liberal third-party pay- 
ment systems. Factors like these plus 'gap filling' induce a rather constant stream of FMG arrivals into the United States and a relatively constant number of them in U.S.-based residencies. It is important to remember that in 1990, there were more than 130000 FMGs in the United States or $21 \%$ of all licensed physicians [12]. Hence, the role of FMGs in U.S. medicine should continue to be of interest to a broad audience.

The curious thing is that this continuous influx of FMGs has occurred despite the enormous growth of USMGs over the last two decades, spawned by large increases in both domestic undergraduate medical education enrollment and the number of domestic medical schools. Figure 1 shows the number of USMG residents compared to the total number of FMG residents over the two-decade period 1971-1991. (Data for this and the remaining figures come from various medical education issues of the Journal of the American Medical Association [13,14].) The steady climb in USMGs is evident. For FMGs, their peak during the early 1970s, their decline in the late 1970s, and their leveling off over the next decade are also evident. However, it is also evident that, for the first time since 1980, there was a decline in 1990 in the total number of USMG residents, although the 1991 figures showed a slight increase over the previous year. The total number of FMG residents has also clearly increased during 1990 and 1991. There seems little question that the

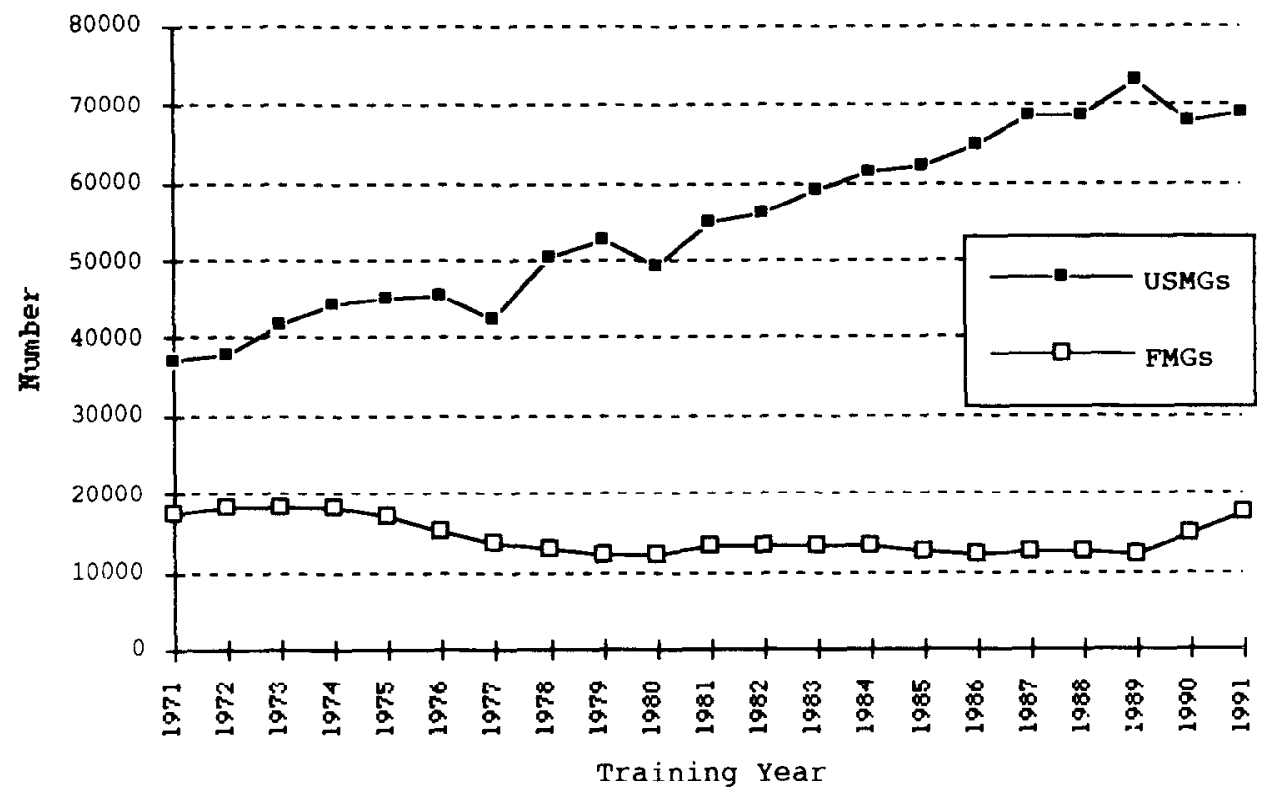

Fig. 1. Number of USMGs and FMGs in Residency Positions, 1971-1991. Source:. Selected Journal of the American Medical Association Medical Education Issues. 
FMG presence in graduate education has assumed an almost permanent status.

Within these data is buried the interesting phenomenon of an absolute and proportionate increase in U.S. citizen FMGs (USFMGs), leading to the conclusion that 'genuine' foreign national FMGs (FNFMGs) have been supplanted by the USFMGs. As is shown in Fig. 2, USFMGs were an almost negligible phenomenon in the early 1970s; indeed, in the years before that period, there were virtually no statistics available on USFMGs. But, USFMGs began increasing steadily from then on, and with the dramatic decline of FNFMGs in the mid- to late-1980s, USFMGs overtook them by 1983 and peaked at slightly over one-half of all FMGs in 1983, 1984, and 1985. However, USFMGs have been a declining fraction ever since then whereas FNFMGs have stayed between a rough band of 5800 and 7000 over the last decade. From 1989 on, there was a surprising increase in the number of FNFMG residents, 9888 to 11910 , or a $20 \%$ increase, making them almost as numerous as they were in 1976. Thus, despite predictions that the FNFMG presence in U.S. graduate medical education would all but disappear, their presence has been maintained and expanded.

Moreover, the increasing numbers of FNFMGs in U.S. residencies has occurred despite the introduction by the ECFMG of the Foreign Medical Graduate Examination in the Medical Sciences (FMGEMS), a two-day basic and clinical science examination, closely patterned after the examination of

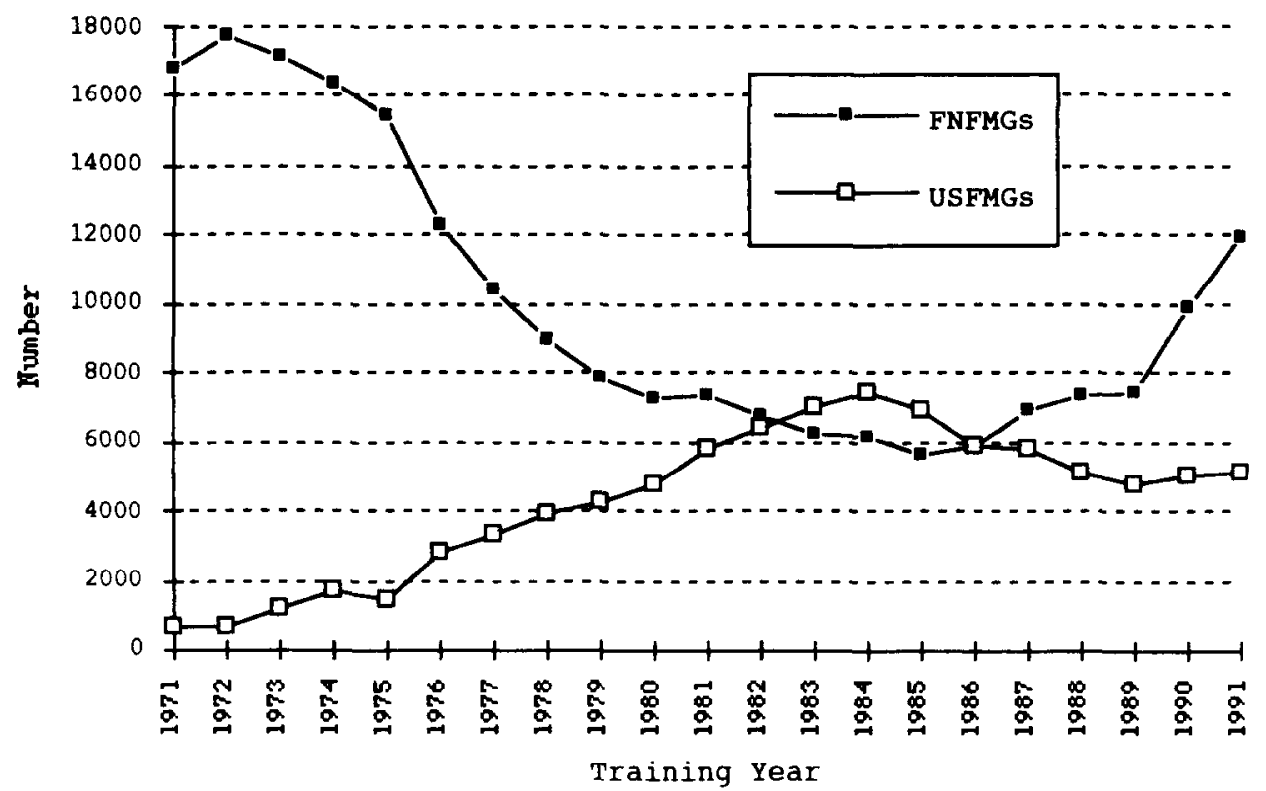

Fig. 2. Number of Foreign National FMGs and U.S. Citizen FMGs in Residency Positions, 1971-1991. Source: Selected Journal of the American Medical Association Medical Education Issues. 
the National Board of Medical Examiners (NBME), and which many, including me [15], erroneously predicted would reduce the inflow of FMGs because it was thought that the FMGEMS would be more difficult to pass than the former standard one-day ECFMG examination. In fact, as Mick and Mou later demonstrated, the pass rate for individuals for the first seven FMGEMS was $23 \%$, with the distinct possibility that the actual pass rate, once examinees had completed all the components of the examination, would reach between 25 and 30\%, figures not altogether different than earlier standard ECFMG examination results [16].

The continual FMG presence is testimony to many different things. One is the increase in the number of unfilled residency posts, a trend of the latter half of the 1980s that reversed the trend of the previous years (Fig. 3). In other words, the demand for residents continued to outstrip the increasing number of USMGs, so that FMGs were afforded a new opportunity for U.S.-based graduate medical education. Thus, there has been a recent convergence of at least three forces that have favored FMG immigration: FMGs' tenacious desire for graduate medical education positions in U.S. hospitals, the propensity of U.S. hospitals to embrace more and more residents in their training programs, and the FMGs apparent willingness to practice medicine in certain locales, specialties, and institutions that USMGs tend to eschew.

The first factor - FMG desire to undertake U.S. graduate medical education - can be inferred from the continuing large number of international medical students and graduates who sit for the ECFMGs examinations. The second factor - an increase in unfilled training posts - is clear from the

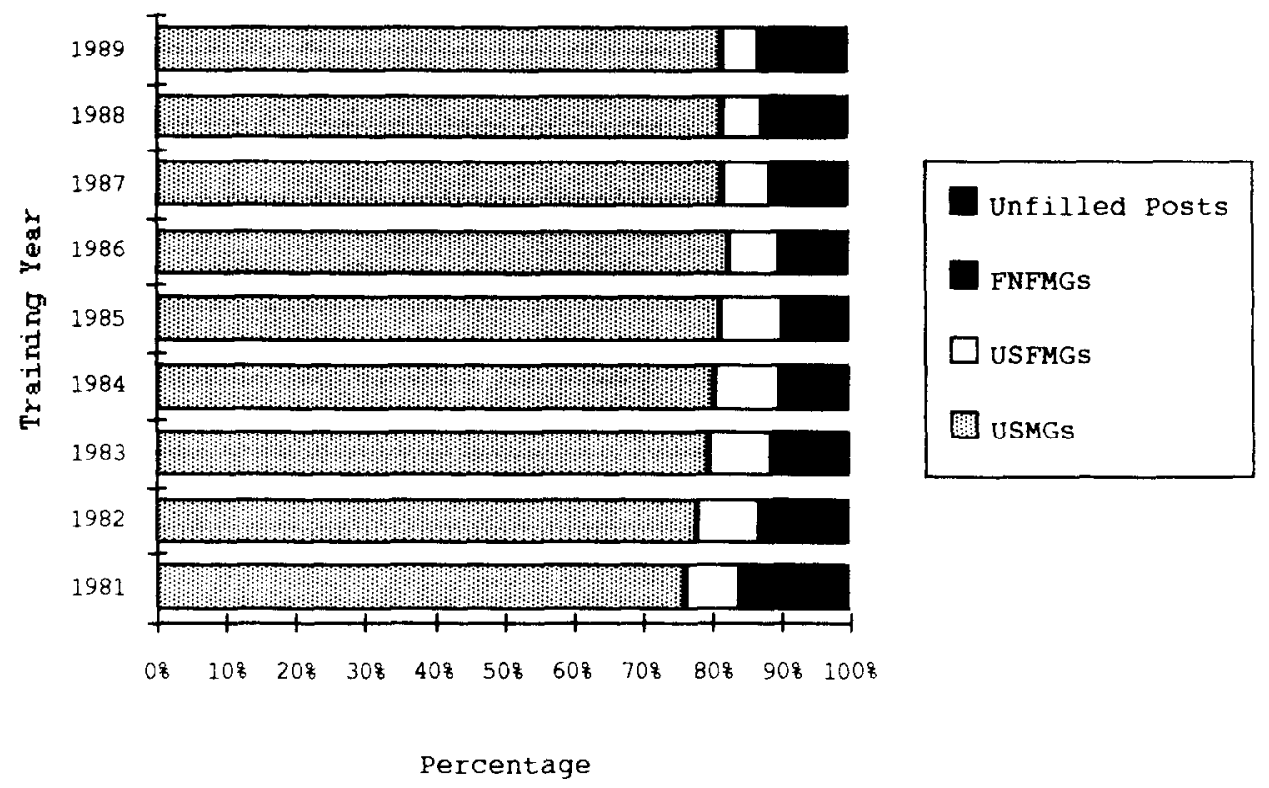

Fig. 3. Percentage of Residency Positions Filled with USMGs, Foreign National FMGs, U.S. Citizen FMGs, and Unfilled, 1981-1989. Source: Selected Journal of the American Medical Association Medical Education Issues. 
data presented in Fig. 3. The third factor - differential role filling by FMGs - has been suggested by a number of studies, already noted.

\section{Differential FMG roles in U.S. medicine}

I argue that the phenomenon of differential FMG-USMG roles may assume an increasing importance. Certain changes in U.S. undergraduate medical education, in the demand for medical services, in the gender composition of physicians, and in the movement toward group practice, make problematic the prediction that a surplus of physicians would exist in the United States as early as 1990 but surely by 2000 and later. If the surplus diminishes, and U.S.-educated physicians behave as they historically have, i.e., avoid medical practice in underserved areas, specialties, and employment settings, opportunities for FMGs may grow. Let us examine several factors potentially contributing to a long-term diminution in the surplus.

\section{Undergraduate medical education}

First, trends in U.S. undergraduate medical education. Figure 4 tells the story quite clearly: since the mid-1970s there has been a steady decline in the number of applicants to U.S. medical schools, although the downward trend has reversed itself in 1990 and 1991, and preliminary information suggests 1992 will sustain the new upward trend. Yet, this recent spurt may be a func-

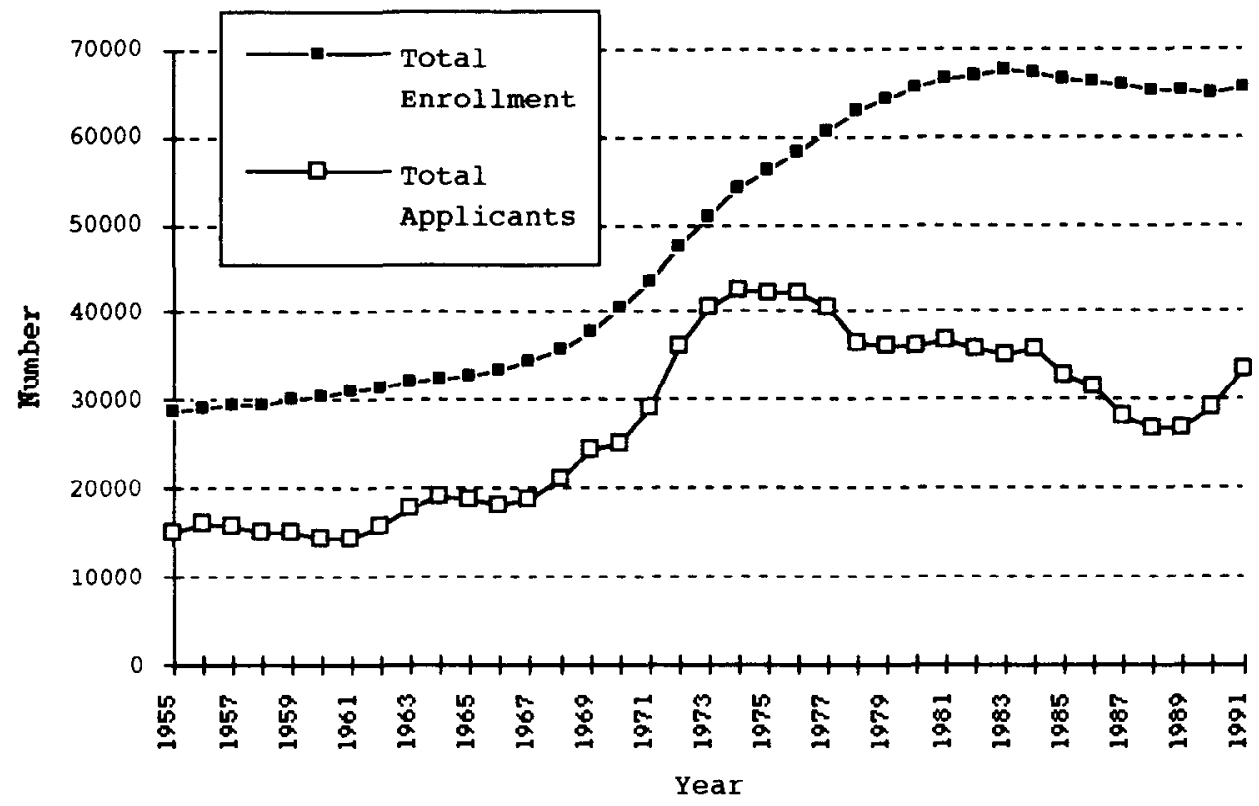

Fig. 4. Total Enrollment and Total Applicants to U.S. Medical Schools, 1955-1991. Source: Selected Journal of the American Medical Association Medical Education Issues. 
tion of poor post-baccalaureate employment opportunities in a stagnant economy with the substitution of more schooling for entry into the job market. This trend must be watched closely.

In any event, Colquitt and Killian report that for the 1989-1990 academic year, the applicant to acceptance ratio was 1.6:1, which made it the lowest in 55 years [17]. Although this now means that applicant-to-acceptance ratios are now approaching the level that they were in the mid-1950s (about two to one) from their peak in the late 1960s and early 1970s (about three to one), the practice of medicine in the 1950s can hardly be compared to that of the 1990s. Specialization and technological sophistication have increased, and the need for the best and brightest of young men and women to master the material of medicine is as high as ever. Yet, Fig. 5 shows a phenomenon that is altogether new in the experience of medical school admissions: from 1981 to 1987 , there was a small but growing number of people admitted to U.S. medical schools but who elected not to attend; the gap has remained relatively constant since then. Always before, almost everyone who was admitted to medical school attended medical school. Whether this indicates that medicine is considered less attractive than other occupational pursuits is a debated question [18]. Surveys of physicians done by the AMA itself reveal a surprising amount of discontent: in $1990,38 \%$ of a random sample of U.S. physicians said they would not recommend medicine as a career choice to a high school or college student who asked for the physician's advice [19]. The same survey showed that MCAT examinees who were qualified

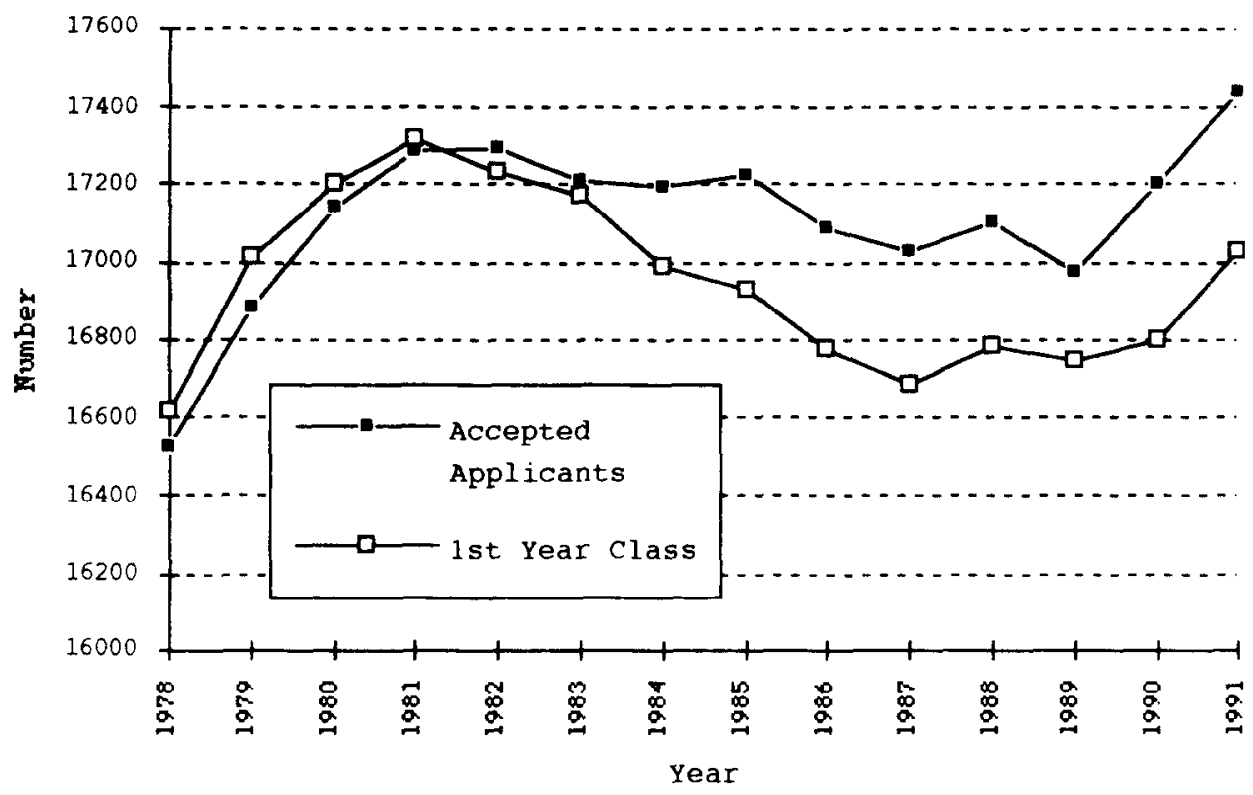

Fig. 5. Number of Accepted Applicants and Number of First Year Enrollees in U.S. Medical Schools, 1978-1991. Source: Selected Journal of the American Medical Association Medical Education Issues. 
to be admitted to medical schools but who did not apply cited $48 \%$ of the time that physicians with whom they spoke had not been 'encouraging about the future of medicine'. Many physicians have developed negative feelings about governmental intrusion in reimbursement and quality of care, malpractice problems, infusion of widespread business practices, and these feelings are apparently being conveyed to a wider public.

One must also consider the hypothesis that medical education may be becoming too expensive for many prospective medical school applicants. Hughes, Barker, and Reynolds noted that the average debt of graduating medical students in 1990 was $\$ 46224$, an increase of $77 \%$ from 1980 , after adjustment for inflation [20]. Rising tuition was noted to be a major cause of this indebtedness. One can only speculate about what measurable effect indebtedness may have had on the numerical decline in the applicant pool, but common sense dictates that it be included in any list of causes.

Another possible factor that may be making medicine less attractive to some is the public and private effort to control fees of patient care physicians. The most notable current effort is the Physician Payment Review Commission (PPRC) recommendation that physicians accept reimbursement for Medicare Part B under a regimen of the Resource Based Relative Value System (RBRVS) developed by health economists at Harvard University. Although the effects of this system are being debated, the cumulative effect of such fee control systems could well be to make medicine less and less attractive to young men and women and to drive older, established physicians out of practice into early retirement.

In sum, medical school first-year classes (16 929 in 1985; 17027 in 1991) and total enrollments have stabilized over the last several years. The period of growth is past. This may well be a response to the fear that surpluses of physicians had been generated as well as to the potential effects of the decreasing size of applicant pools. Class size stabilization could also be due in part to the improbability of any new increases in governmental largesse to medical education given the strains of the federal deficit and in state budgets.

\section{Demand for medical services}

If the U.S. population continues to grow in its demands for medical services, just as it has ever since the end of World War Two, there could well be pressure for more, not less, immigration of FMGs to make up whatever difference there might be between the supply of U.S. physicians and national requirements for their services. Arguments, controversial though they be, are appearing from various sources that increasing demand for medical services has continued to befuddle the best projections of the balance between medical resources and needed requirements. For example, Schwartz and Mendelson have estimated that the total hours that physicians spent in patient care rose $21 \%$ from 1982 to 1987 , whereas the physician supply rose by only $16 \%$, suggesting a sharp increase in demand for services [21]. They conclude that no physician surplus can be expected under these cir- 
cumstances. In another study, Schwartz, Sloan, and Mendelson showed that patient demand for services until 2000 is likely to increase at least at the rate of physician supply [22]. Major contributing factors to the increased demand including the research and care surrounding the victims of the AIDS epidemic and the aging of the U.S. population. It is possible that under a new Democratic administration, health finance reform will constrain demand for services, and this prospect should be carefully watched.

\section{Women in medicine}

The number of women in medical school has risen dramatically since the early 1970s (Fig. 6). At the same time, the number of men has dropped. If, as some studies report, female physicians work on average fewer hours per week and fewer weeks per year than male physicians (at least a partial result of child rearing responsibilities not having been assumed by men [23]), then the overall productivity at a given moment of the women would be somewhat lower than if all physicians had been men [24]. To be more precise, in an earlier study of 87 female and 95 male physicians in the Detroit area, Heins, Smock, Martindale, Jacobs, and Stein reported that female physicians spent about $90 \%$ as much time in medicine as did male physicians [25]. A $10 \%$ difference means that about 111 female physicians would be required to supply the services of 100 male physicians. Hence, as women become a larger proportion of the physician pool, the prediction would be that proportionately

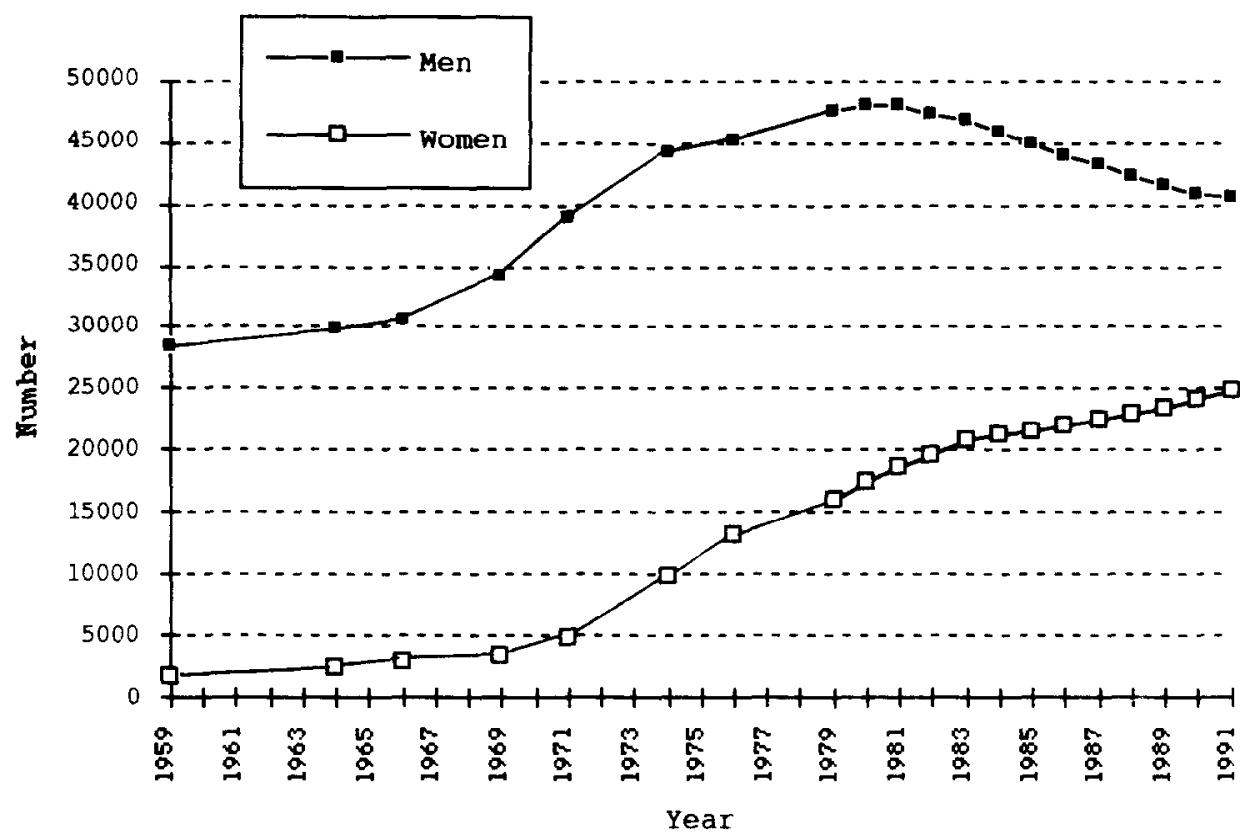

Fig. 6. Total U.S. Medical School Enrollment for Men and Women, Selected Years, 1959-1991. Source: Selected Journal of the American Medical Association Medical Education Issues. 
more women would be needed to maintain the supply equivalent of a given number of men, other things being equal. Another study countered by noting that these productivity differences, including an on average earlier female retirement age, are somewhat offset by higher female longevity [26]. Still, at a given moment in time, a productivity differential exists, and just cited study's prediction is that the effective full time equivalent measure of physician services will decline by about 4\% between 1986 and 2010 due to the changing male-female composition of the physician pool, other things being equal.

\section{Growth in group practice}

The movement of physicians - male and female - toward group practices, both fee-for-service and prepaid, means generally shorter working hours as compared to more traditional practices in which there are fewer constraints on income, fees, hours worked, and ancillary personnel used to increase income, fees, and total time worked. For example, the percent of patient care physicians in group practices increased from $24 \%$ in 1980 to $33 \%$ in 1988 [27]. Hence, another limit to overall productivity of physicians appears to be strengthening. This may add to the need to increase the number of physicians to meet growing demand for medical and health care.

\section{Conclusion}

It could well be these scenarios will not be as extreme as I have described; guessing the future is always risky business, and many of the points are contentious. Yet, there seems to be little doubt that in the early part of the last decade of the 20th Century, the future of U.S. medical personnel is less clearly discernible than we thought it was when we entered the $1980 \mathrm{~s}$.

It is now possible to entertain the idea that we are not facing a physician surplus of the magnitude originally predicted. In some specialties, GMENAC-predicted shortages continue to exist: the trend in primary care, defined as family and general practice, pediatrics, and general internal medicine, is actually declining: 45 and $38 \%$ of physicians were training in these specialties in 1980 and 1990, respectively [28]. Additionally, it seems likely that physician productivity will be constrained in important ways. Although we know that the past abundance of U.S.-trained physicians has led to some diffusion of medical personnel into previously underserved areas geographically [29], the extent of this diffusion is contested [30-32]. Furthermore, other dimensions of under service (e.g., specialty or type of practice) remain problematic. In short, there is, in my view, the real possibility of a future confluence of constraints on domestic physician supply and overall productivity and of continuing problems of under service and maldistribution.

Many hospitals continue to rely heavily on FMG house officers, and the apparently insatiable appetite of hospitals generally for residents acts as a 
'pull' factor for FMGs. with the Educational Commission for Foreign Medical Graduate's (ECFMG) substitution of the National Board of Medical Examiners' (NBME) test for the FMGEMS, the low pass rate of FMGs might be expected to act as yet another barrier to their inflow into U.S. residencies [33]. However, historically, FMGs have improved their pass rates on each of the various examinations that the ECFMG has adopted, and there is no reason to suspect that NBME pass rates for FMGs will not equilibriate around the $25-30 \%$ range. The NBME test may not pose anything more than a temporary limit on FMG study in the United States.

Lacking health policy reform that reduces questionable and inappropriate diagnostic and therapeutic medical and surgical procedures, that constrains the training of specialists, that limits malpractice exposure which, in turn, influences so-called 'defensive medicine', that creates greater incentives for physicians to practice in underserved areas, specialties, and employment settings, the same forces that skew U.S. medical graduates' career choices will also skew those of many FMGs. It is a coexisting and paradoxical set of two factors - 'gap filling' and mimicking mainstream U.S. medicine - that probably will continue to attract FMGs.

In short, the forces that have historically led to the United State's reliance on FMGs are still present and show signs of renewed strength. There may be more, not fewer, avenues into U.S. medical practice that could open up for FMGs, leading to a new generation of U.S.-based graduate medical education training and a new cycle of permanent residence. The evidence is already pointing in this direction. Furthermore, it may be time for policy makers, legislators, medical educators, and academics alike to recognize that the United States - as it is in so many other realms - is permanently involved in international exchange and is a sought after destination for immigrants of all occupations.

It is unclear that the FMG issue should 'go away' in that FMG supply should be shut off; rather, there should be acknowledgment that FMGs have contributed and will contribute to U.S. medicine in important ways. Little in the way of public or private effort over the last generation has shown any will to staunch the flow of FMGs to the United States; it may be more useful now to recognize this, understand the various reasons why it has happened, and to improve the current and future training of the many thousands of FMGs who annually establish-practices here. The new architects of U.S. health policy must be aware of the role FMGs have historically played in U.S. medicine and draft new policies sensibly so that equity for FMGs, both those who train in the United States and return to their home countries and those who have immigrated, as well as for their U.S. patients, is maintained.

\section{References}

1 Graduate Medical Education National Advisory Committee, Summary Report to the Secretary, Department of Health and Human Services, Vol. I, Washington, DC, US Government Printing Office, September 30, 1980. 
2 U.S. Department of Health and Human Services, Bureau of Health Professions, Seventh Report to the President and Congress on the Status of Health Personnel in the United States, Washington, DC, US Government Printing Office, DHHS Pub. No. HRS-P-OD90-1, March 1990), pp. VI-52, Table VI-A-17.

3 Center for Health Policy Research, The demographics of physician supply: trends and projections, Chicago, American Medical Association, 1987, p. 41, Table 16.

4 Reinhardt, U.E., The GMENAC forecast: an alternative view, American Journal of Public Health, 71 (1981) 1149-1157.

5 Bowman, M. and Walsh, W.B., Jr., Perspectives on the GMENAC report, Health Affairs, 1 (1982) 55-66.

6 Mick, S.S., Contradictory policies for foreign medical graduates, Health Affairs, Fall (1987) 5-18.

7 U.S. Department of Health and Human Services, Bureau of Health Professions, Seventh Report to the President and Congress on the Status of Health Personnel in the United States, (Washington, DC, US Government Printing Office, DHHS Pub. No. HRS-P-OD90-1, March 1990, pp. VI-35, 45, Tables VI-A-2, VI-A-12.

8 Ginzberg, E., Physician supply policies and health reform, Journal of the American Medical Association, 268 (December 2, 1992) 3115-3118.

9 Mick, S.S. and Worobey, J.L., Foreign and United States medical graduates in practice: a follow-up, Medical Care, 22 (1984) 1014-1025.

10 Mick, S.S., Sector theory, stratification, and health policy: foreign and US medical graduates in medical practice, Journal of Health and Social Behavior, 28 (1987) 74-88.

11 Mick, S.S. and Rubino, F., The 1987 geographic location of foreign and US medical graduates: distribution of physicians who entered the US medical system between 1969 and 1982, University of Michigan, Unpublished manuscript, 1992.

12 Page, L., Dr. Todd condemns unequal licensure policies for IMGs, American Medical News, 2 (May 13, 1991), 26.

13 Jonas, H.S., Etzel, S.I. and Barzansky, B., Educational programs in US medical schools, Journal of the American Medical Association, 268 (September 2, 1992) 1083-1089.

14 Graduate medical education, Journal of the American Medical Association, 268 (September 2, 1992) 1170-1176.

15 Mick, S.S. and Worobey, J.L., The future role of foreign medical graduates in US medical practice: projections into the 1990s, Health Services Research 21, (1986) 85-106.

16 Mick, S.S. and Mou, T.W., The foreign medical graduate examination in the medical sciences (FMGEMS): an analysis of pass rates of the July 1984-July 1987 examinations, Medical Care, 29 (1991) 229-242.

17 Colquitt, W.L. and Killian, C.D., Students who consider medicine but decide against it, Academic Medicine, 66 (May 1991) 273-278.

18 Jolly, P., Changes in the character of the student body in US medical schools, The Journal of Medical Practice Management, 5 (1989) 144-148.

19 Harvey, L.K. and Shubat, S.C., Physician opinion on health care issues, Chicago: American Medical Association, April 1990.

20 Hughes, R.G., Barker, D.C. and Reynolds, R.C., Are we mortgaging the medical profession? The New England Journal of Medicine, 325 (August 8, 1991) 404-407.

21 Schwartz, W.B. and Mendelson, D.N., No evidence of an emerging physician surplus: an analysis of change in physicians' work load and income, Journal of the American Medical Association, 263 (January 26, 1990) 557-560.

22 Schwartz, W.B., Sloan, F.A. and Mendelson, D.N., Why there will be little or no physician surplus between now and the year 2000, New England Journal of Medicine, 318 (April 7, 1988) 892-897. 
23 Weisman, C.S. and Teitelbaum, M.A., The work-family role system and physician productivity, Journal of Health and Social Behavior, 28 (1987) 247-257.

24 Lanska, M.J., Lanska, D.J. and Rimm, A.A.. Effect of Rising percentage of female physicians on projections of physician supply, Journal of Medical Education, 59 (1984) $849-855$.

25 Heins, M., Smock, S., Martindale, L., Jacobs, J. and Stein, M., Comparison of the productivity of women and men physicians, Journal of the American Medical Association. 237 (1977) 2514-2517.

26 Kletke, P.R., Marder, W.D. and Silberger, A.B., The growing proportion of female physicians: implications for U.S. physician supply, American Journal of Public Health. 80 (March 1990) 300-304.

27 Wyszewianski, L. and Mick, S.S., Medical Care Chartbook. 9th Edition, Ann Arbor: Health Administration Press, 1991, Chart E-29, p. 177.

28 Mick, S.S. and Moscovice, I., Health Care Professionals, In S.J. Williams and P.R. Torrens (Eds.), Introduction to Health Services, Chapter 10. 4th Edition, Albany, NY, DelMar Publishers Inc., 1993.

29 Newhouse, J., Geographic access to physician services, Annual Review of Public Health, 11 (1990) 207-230.

30 Hicks, L., Social policy implications of physician shortage areas in Missouri, American Journal of Public Health, 74 (1984) 1316-1321.

31 Hicks; L., Availability and accessibility of rural health care, Journal of Rural Health, 6 (October 1990) 485-505.

32 Kindig, D.A. and Movassaghi, $H$., The adequacy of physician supply in small rural communities, Health Affairs, 8 (1989) 63-76.

33 Page, L., Test results disappointing for fmgs' first national boards, American Medical News, (December 8, 1989) 3, 34. 